\title{
Coronary venous lipid peroxide concentrations after coronary angioplasty: correlation with biochemical and electrocardiographic evidence of myocardial ischaemia
}

K G Oldroyd, J R Paterson, A G Rumley, H Eteiba, A P Rae, J Shepherd, S M Cobbe, I Hutton inflations each produce a similar degree of myocardial ischaemia. The origin of the raised lipid peroxide concentrations in coronary venous plasma after angioplasty remains unknown.

Oxygen derived free radicals are produced during reperfusion of the ischaemic myocardium. ${ }^{12}$ Such free radical activity is difficult to measure directly in humans, but can result in oxidative damage to polyunsaturated membrane phospholipids with the production of relatively stable lipid peroxides. Plasma lipid peroxides are most commonly measured by catalysing their degradation to malondialdehyde, which reacts with thiobarbituric acid to form an adduct. Thus lipid peroxide concentration is normally expressed as $\mu \mathrm{M}$ of malondialdehyde and includes any free malondialdehyde that is also present in plasma. We have previously identified raised lipid peroxide concentrations in coronary venous blood after myocardial ischaemia induced by pacing. $^{3}$ During percutaneous transluminal coronary angioplasty, recurrent brief periods of myocardial ischaemia are followed by reperfusion, and this sequence might be expected to provoke free radical generation. In an initial study of patients undergoing angioplasty of the left anterior descending coronary artery, we sampled coronary venous blood two and 10 minutes after the last balloon inflation but failed to show any increase in lipid peroxide concentrations. ${ }^{4}$ Studies in which coronary venous blood had been sampled immediately after balloon inflation(s) have reported negative ${ }^{5}$ and positive ${ }^{67}$ results. Recent animal studies have indicated that there is a positive relation between the severity of preceding myocardial ischaemia and the degree of subsequent reperfusion injury due to oxygen radicals. ${ }^{89}$ If, in patients undergoing coronary angioplasty, the production of lipid peroxides is related to preceding cycles of ischaemia and reperfusion it may be possible to correlate lipid peroxide concentrations with the degree of ischaemia produced during balloon inflation.

Patients and methods

Fifteen patients (age range 42-70; 12 men) with
Correspondence to K G Oldroyd, Department of Medical Cardiology, Royal Infirmary, 10 Alexandra
Parade, Glasgow G31 2ER. Accepted for publication 24 October 1991 \begin{abstract}
with lipid peroxide concentrations.
Conclusions-Raised lipid pero concentrations in coronary ve balloon angioplasty. There is no positive correlation between lipid peroxide concentrations in coronary venous plasma after angioplasty and the degree of preceding myocardial ischaemia as assessed by either ST segment shift or lactate production. These indices showed that one to three serial 60 second balloon
\end{abstract}


Table 1 Peak lipid peroxide and lactate concentrations in the great cardiac vein before and after one to three serial 60 second balloon inflations in the left anterior descending artery

\begin{tabular}{|c|c|c|c|}
\hline & No & $\begin{array}{l}\text { Lipid peroxides }(\mu M) \\
\text { Mean }(95 \% \mathrm{CI})\end{array}$ & $\begin{array}{l}\text { Lactate (mM) } \\
\text { Mean }(95 \% C I)\end{array}$ \\
\hline $\begin{array}{l}\text { Before PTCA } \\
\text { 1st inflation } \\
\text { 2nd inflation } \\
\text { 3rd inflation } \\
\text { After PTCA }\end{array}$ & $\begin{array}{l}15 \\
15 \\
11 \\
10 \\
15\end{array}$ & $\begin{array}{l}3.4(3.1 \text { to } 3.6) \\
4.0(3.7 \text { to } 4.2)^{\star} \\
3.7(3.4 \text { to } 4.0)^{\star} \\
3.9(3.6 \text { to } 4 \cdot 2)^{\star} \\
3.3(3.1 \text { to } 3.6)\end{array}$ & $\begin{array}{l}1.2(1.0 \text { to } 1.5) \\
2.7(2.4 \text { to } 2.9)^{\star} \\
2.4(2.2 \text { to } 2.7)^{\star} \\
2.6(2.2 \text { to } 2.9)^{\star} \\
1.2(1.0 \text { to } 1.5)\end{array}$ \\
\hline
\end{tabular}

PTCA, percutaneous transluminal coronary angioplasty.

^All significantly greater than values before or after PTCA $(p<0.01)$

stable angina pectoris undergoing angioplasty of a stenosis in the proximal left anterior descending coronary artery were studied. Three patients had had previous myocardial infarctions (one anterior, two inferior), all more than 12 months before the study. All regular medications were continued including calcium antagonists (12), $\beta$ adrenoceptor antagonists (five), nitrates (nine), and $150 \mathrm{mg}$ aspirin daily (15 patients). Blood samples from the great cardiac vein were taken with a $7 \mathrm{~F}$ Gensini catheter placed through a left antecubital fossa vein. The position of the catheter was confirmed radiologically. All samples were taken after systemic heparinisation. Simultaneous aortic and coronary venous samples of $20 \mathrm{ml}$ were taken before the first inflation and at the end of the procedure. Additional coronary venous samples of $10-12 \mathrm{ml}$ were taken 0,30 , and 60 seconds after each inflation up to a maximum of five inflations per patient. Serial samples were taken to avoid missing the period of peak release of lactate or lipid peroxides. In the final three patients serial aortic and coronary venous blood was sampled simultaneously but only after the first inflation. All inflations were of 60 seconds duration. The protocol was appoved by the ethics committee, Glasgow Royal Infirmary and patients gave informed written consent.

\section{ASSAYS}

Lipid peroxides were measured in plasma (with added ethylenediaminetetra-acetic acid (EDTA)) by high performance liquid chromatography according to a modification of a previously described method. ${ }^{410}$ Many other compounds, including some drugs, can interfere in the thiobarbituric acid assay for lipid peroxides. With high performance liquid chromatography we aimed to reduce such interference compared with older methods that use spectrophotometric or fluorimetric techniques. Mean (SD) concentration from repeated measurements in this assay was 3.8 $\mu \mathrm{M}(0.3)$ giving a coefficient of variation of $8 \% .{ }^{11}$ Lactate concentration was measured by a commercially available enzymatic assay (Boehringer Diagnostica, Mannheim) with an intra-assay coefficient of variation of $0 \cdot 7 \%$. The maximum ST segment shift in any of the 12 electrocardiographic leads recorded continuously throughout each balloon inflation was measured manually by an operator who was not aware of the results of the lactate or lipid peroxide measurements.

\section{STATISTICS}

The distribution of each variable was assessed by calculating the standardised coefficients of skewness and kurtosis. All of the data were normally distributed and so the summary statistic employed is mean and $95 \%$ confidence interval $(95 \% \mathrm{CI})$. Repeated measures analysis of variance was used to assess the overall statistical significance of the differences between lipid peroxide and lactate concentrations, and the ST segment shift at different times. Thereafter Bonferroni corrected $t$ tests were used. Linear regression analysis was performed to examine the relation between variables. All statistical analyses were carried out with a PC version of Statgraphics (STSC Inc, Maryland, USA).

\section{Results}

The aortocoronary lipid peroxide gradient was $0.2(0.0$ to 0.4$) \mu \mathrm{mol} / 1$ before angioplasty and $-0.2(-0.4$ to 0.0$) \mu \mathrm{mol} / 1$ five minutes after the final inflation $(p=0.03)$. The aortocoronary lactate gradients at the same times were 0.0 $(-0.2$ to 0.2$) \mu \mathrm{mol} / \mathrm{l}$ and $-0.1(-0.3$ to 0.1$)$ $\mu \mathrm{mol} / \mathrm{l}(\mathrm{p}=0.86)$.

\section{Lipid peroxide concentrations in the great cardiac} vein

No increases above pre-angioplasty concentrations occurred in two patients. The percentage of samples in the other 13 patients with concentrations above pre-angioplasty values ranged from $25 \%$ to $100 \%$ per patient. Overall, 82 of $136(60 \%)$ samples assayed were raised. The peak concentration was seen at zero seconds in $32 \%$ of inflations, at 30 seconds in $39 \%$, and at 60 seconds in $29 \%$. The peak concentration after each of the first three serial dilatations was significantly greater than both the pre and postangioplasty samples, which were not different from each other (table 1). The peak percentage increase from pre-angioplasty values exceeded 2 SDs of the relevant measurement error $(16 \%)$ after 27 out of $46(59 \%)$ inflations (fig 1). There was no significant difference between the peak percentage change after any of the first three serial inflations (table 2).

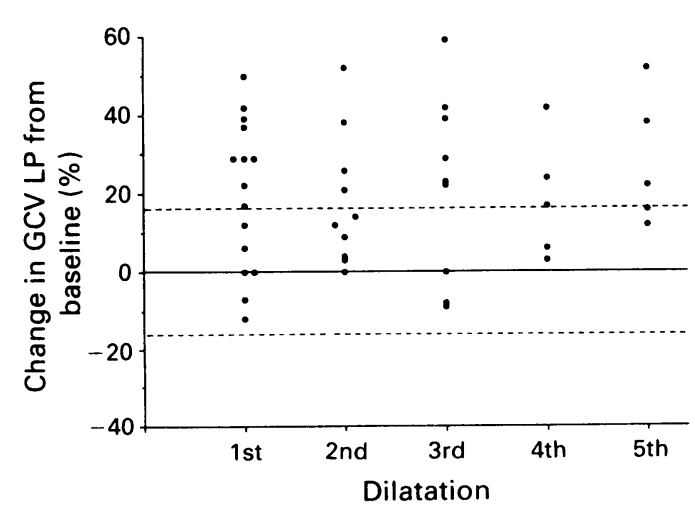

Figure 1 Individual peak percentage change in the concentration of lipid peroxide in the great cardiac vein (GCV LP) after one to five serial balloon inflations in the left anterior descending coronary artery. The broken line indicates $2 S D$ s of the error of repeated measurements (see text). 
Table 2 Percentage change, mean (95\% CI), from pre-angioplasty values of peak lipid peroxide (LP) and lactate concentrations in the great cardiac vein, and maximum $S T$ segment shift after 1-3 serial 60 second balloon inflations in the left anterior descending artery

\begin{tabular}{|c|c|c|c|c|}
\hline & No & $\begin{array}{l}\text { Lipid } \\
\text { peroxides (\%) }\end{array}$ & Lactate (\%) & $\begin{array}{l}\text { ST segment } \\
\text { shift }(\mathrm{mm})\end{array}$ \\
\hline $\begin{array}{l}\text { First inflation } \\
\text { Second inflation } \\
\text { Third inflation }\end{array}$ & $\begin{array}{l}15 \\
11 \\
10\end{array}$ & $\begin{array}{l}20(13 \text { to } 26) \\
17(9 \text { to } 25) \\
24(15 \text { to } 32)\end{array}$ & $\begin{array}{l}147(72 \text { to } 222) \\
141(54 \text { to } 229) \\
167(70 \text { to } 264)\end{array}$ & $\begin{array}{l}0.8(0.6 \text { to } 1.1) \\
0.9(0.6 \text { to } 1.1) \\
0.9(0.6 \text { to } 1.2)\end{array}$ \\
\hline
\end{tabular}

No significant differences were found between values of any indices after first, second, or third inflations.
Figure 2 Individual peak percentage change in lactate concentration in the great cardiac vein ( $G C V$ ) after one to five serial balloon inflations in the left anterior descending coronary artery.
Lactate concentrations in the great cardiac vein No increases above pre-angioplasty concentrations were seen in any of the samples from one patient. This patient also showed no electrical evidence of ischaemia but did have raised lipid peroxide concentrations. The percentage of samples in the other 14 patients with concentrations above pre-angioplasty values ranged from $33 \%$ to $100 \%$ per patient. Overall, 104 out of $122(85 \%)$ of samples assayed were raised. The peak concentration was seen at zero seconds in $79 \%$, at 30 seconds in $15 \%$, and at 60 seconds in $6 \%$ of cases. The peak concentrations immediately after each of the first three inflations were significantly greater than both the pre and post-angioplasty samples, which were not different from each other (table 1 ). The peak percentage increase from pre-angioplasty values exceeded 2 SDs of the measurement error $(1.4 \%)$ after 43 out of $46(93 \%)$ inflations (fig 2). There was no significant difference in the peak percentage changes between any of the first three serial inflations (table 2).

\section{Electrocardiographic changes}

There was no significant difference in the maximum ST segment shift occurring between any of the first three serial inflations (table 2).

\section{Correlations}

A significant positive correlation was found between peak lactate concentrations in the great cardiac vein and maximum ST segment shift after each balloon inflation. No correlation was shown, however, between peak lactate and lipid peroxide concentrations in the great cardiac vein. There was a significant negative correlation between the peak concentrations of lipid peroxides in the great cardiac vein and maximum ST segment shift (fig 3).

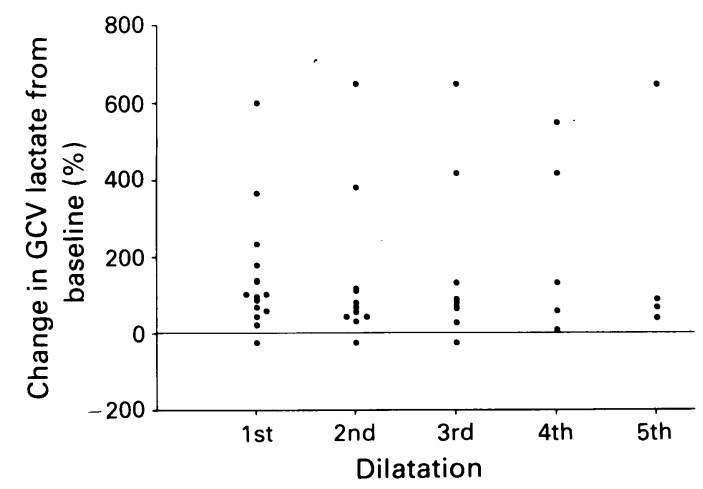

\section{Discussion}

This study confirms that raised concentrations of lipid peroxides can be detected in coronary venous blood after angioplasty. It has been suggested that the production and release of lipid peroxides during coronary balloon angioplasty result from free radical mediated damage to polyunsaturated membrane lipids after cycles of myocardial ischaemia and reperfusion. ${ }^{7}$ Our results suggest that no relation exists between lipid peroxide concentrations in coronary venous plasma after angioplasty and the degree of preceding myocardial ischaemia as assessed by either ST segment shift or lactate production. There are several possible explanations for this finding.

Firstly, we may not have produced a large enough ischaemic insult to initiate reperfusion injury. Aside from the evidence linking the degree of reperfusion injury to the extent of the preceding ischaemia as outlined in the introduction, there is some evidence that only zero flow ischaemia before reflow results in oxygen radical mediated peroxidation of membrane lipids. ${ }^{1213}$ We cannot determine the
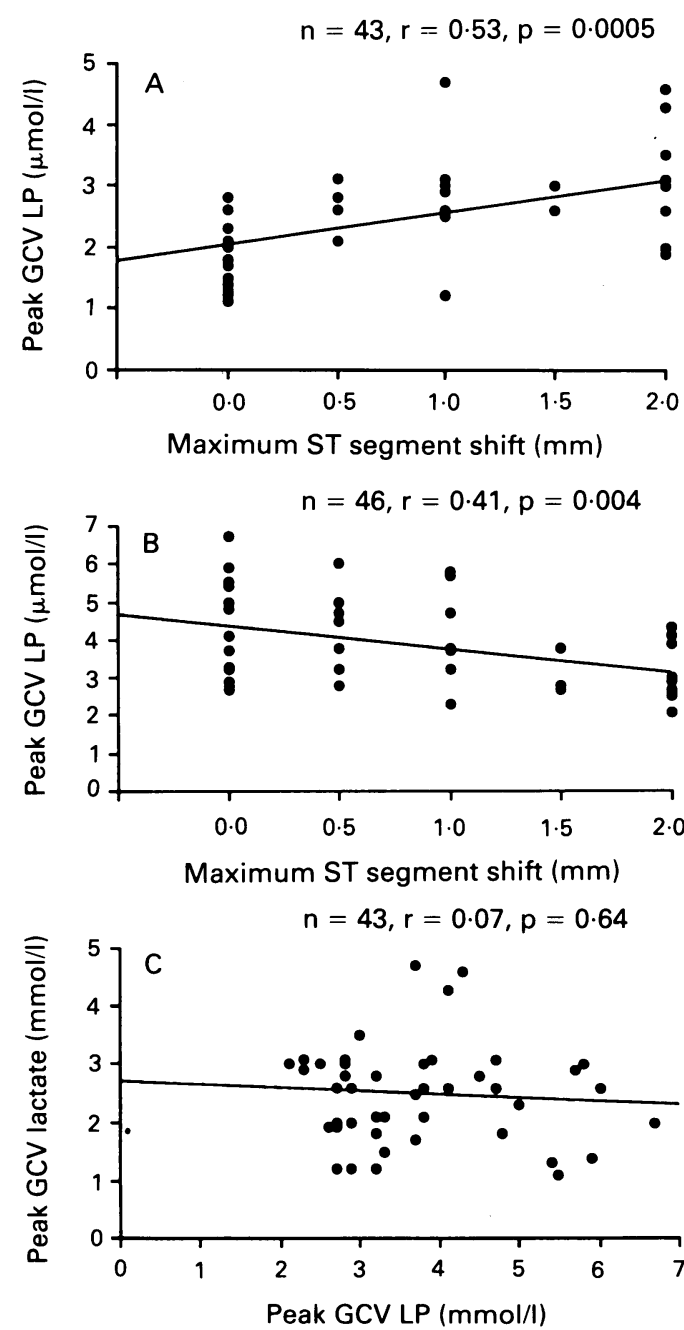

Figure 3 Simple linear regression analysis of the relation between: (A) peak lactate concentration in the great cardiac vein (GCV) and maximum $S T$ segment shift $;(B)$ peak $G C V$ lipid peroxide $(L P)$ concentration and maximum $S T$ segment shift; (C) peak $G C V L P$ concentration and lactate concentration. 
degree of residual perfusion present during balloon inflation in our patients.

Secondly, even if severe or zero flow ischaemia were produced, we cannot be sure that the coronary venous catheter was sampling the effluent from the ischaemic area. The difficulties of assessing regional myocardial metabolism by coronary venous sampling are well known. ${ }^{14}$ By sampling far into the great cardiac vein only in patients undergoing angioplasty of relatively proximal left anterior descending artery stenoses we hoped to minimise this potential problem. In 14 out of 15 cases measurements of lactate concentration confirmed that the coronary venous catheter was draining an area of at least partially ischaemic myocardium.

Thirdly, the actual sampling protocol itself may not have enabled the true trans-myocardial release of lipid peroxides to be measured. Serial samples were taken after balloon deflation, but it is possible that even frequent measurements of the concentration of a metabolite may miss the moment of peak production, particularly in the absence of any knowledge of flow. The rapid and dynamic changes in coronary artery blood flow during balloon angioplasty are such that the accurate measurement of the maximum rate of production of any metabolite would require simultaneous and continuous measurement of metabolite concentration and coronary flow. ${ }^{16}$ This is not technically feasible at present. Baseline samples from the great cardiac vein were not taken before each inflation, but for all inflations studied, mean concentrations of both lactate and lipid peroxides were not significantly different from pre-angioplasty concentrations 60 seconds after reperfusion, a finding consistent with earlier data. ${ }^{7}$ Ideally, one should sample simultaneously in the aorta and great cardiac vein to be certain that any changes detected in concentrations in the great cardiac vein are occurring across the coronary circulation. We did this in our final three patients and found, as did other groups, no evidence of any consistent change in the arterial concentrations of either lactate or lipid peroxides during coronary angioplasty. ${ }^{5-7}$

Finally, the coronary venous effluent may not reflect peroxidation of lipids within the reperfused myocardium. Studies that have measured products of lipid peroxidation in the coronary effluent and in different subcellular fractions of reperfused hearts have indicated that although there is a small rise in the lipid peroxide content of the coronary effluent after reperfusion, myocardial lipid peroxidation occurs predominantly in the membranes of certain intracellular organelles. ${ }^{1317}$ It is doubtful whether these lipid peroxides are free to cross the cell membrane and extracellular space and enter the circulation.

Notwithstanding these considerations the lack of any positive correlation between either the electrical or biochemical evidence of ischaemia and the raised lipid peroxide concentrations suggests that production of these can be, at best, only partly due to damage mediated by oxygen radicals after post-ischaemic reflow.
Other possible sources include the mechanically disrupted atherosclerotic plaque, which is known to contain substantial amounts of lipid peroxides, ${ }^{1819}$ platelets, ${ }^{20} 21$ leucocytes, and endothelial cells. These cells are all capable of producing prostaglandins, or leucotrienes, or both, and peroxides may be formed during their biosynthesis. ${ }^{22} 23$ Even though all of our patients were taking aspirin, which interferes with the synthesis of peroxides by the cyclooxygenase enzyme system, ${ }^{21}$ it is unlikely that this pathway was completely inactivated.

Irrespective of their origin, what consequences might the release of these lipid peroxides have? Lipid peroxides can selectively inhibit prostacyclin $\left(\mathrm{PGI}_{2}\right)$ synthesis ${ }^{24}$ and through effects on antithrombin III activity 25 induce thrombin generation in normal plasma. ${ }^{27}$ These prothrombotic effects could play a part in the pathogenesis of both acute occlusion and late restenosis after coronary angioplasty. Studies are needed to explore these potential mechanisms of disease and to identify the origin of the increased lipid peroxide concentrations found after angioplasty.

A secondary conclusion from the results of this study is that when 60 second balloon inflations are used, the degree of myocardial ischaemia produced during angioplasty is similar after at least three serial inflations. In animal models short earlier periods of coronary occlusion can protect against ventricular arrhythmias during 'a subsequent sustained ischaemic insult. ${ }^{28}$ This is known as ischaemic preconditioning. The exact timing of the sequences of ischaemia and reperfusion necessary to produce preconditioning and the underlying mechanisms are not clear. Several groups have used the situation of coronary angioplasty to explore this phenomenon in humans. Our finding of an absence of preconditioning with 60 second coronary occlusions is consistent with the results of three previous studies. ${ }^{30} 3132$ Other workers using 90 second inflations have shown a lesser degree of ischaemia after a second inflation. ${ }^{33} 34$

Differences in patient selection, the method of quantifying ischaemia, and the degree of collateral flow during balloon occlusion may go a long way towards explaining these opposing results. Alternatively, it may be the case that there is a critical occlusion time needed to initiate the preconditioning mechanism, this time being greater than 60 seconds. The results of further studies specifically designed to consider these questions are awaited with interest.

We thank the Chest, Heart and Stroke Association (Scotland) for support. KGO is a British Heart Foundation junior research fellow.

1 Kramer JH, Arroyo CM, Dickens BF, Weglicki WB. Spintrapping evidence that graded myocardial ischemia alter post-ischemic superoxide production. Free Radic Biol Med 1987;3:153-9.

2 Bolli R, Bharat SP, Jeroudi MO, Lai EK, McCay PB Demonstration of free radical generation in "stunned" myocardium of intact dogs with the use of the spin trap alpha-phenyl N-tert-butyl nitrone. J Clin Invest 1988;82:476-85.

3 Oldroyd KG, Chopra M, Rankin AC, Belch JJF, Cobbe SM. Lipid peroxidation during myocardial ischaemia induced by pacing. Br Heart $J$ 1990;63:88-92.

4 Paterson JR, Oldroyd KG, Rumley AG, et al. Free radical 
activity during percutaneous trans-luminal coronary angioplasty. Biochem Soc Trans 1990;18:1183-4.

5 Steg PG, Pasquier C, Pham T, et al. Evidence for neutrophil and complement activation early a

6 Scerder IK ardiol 1990;15:164A. Serruys PW. Malondialdehyde and uric acid release as a Serruys PW. Malondialdehyde and uric acid release as a
result of PTCA [Abstract]. J Am Coll Cardiol result of

7 Roberts MJD, Young IS, Trouton TG, et al. Transient release of lipid peroxides after coronary artery balloon angioplasty. Lancet 1990;336:143-5.

8 Ambrosio G, Becker LC, Hutchins GM, Weisman HF, Weisfeldt ML. Reduction in experimental infarct size by recombinant human superoxide dismutase: Insights int the pathophysiology of reperfusion injury. Circulation 1986;74:1424-33.

9 Bolli R, Jeroudi MO, Patel BS, et al. Marked reduction of free radical generation and contractile dysfuncton by antioxidant therapy begun at the time of reperfusion: evidence that myocardial "stunning" is a manifestation of reperfusion injury. Circ Res 1989;65:607-22.

10 Therasse J, Lemonnier F. Determination of plasma lipoperoxides by high-performance liquid chromatography. J Chromatogr 1987;413:237-41.

11 Bland JM, Altman DG. Statistical methods for assessing agreement between two methods of clinical measurement. agreement between two
Lancet 1986 ;(i):307-10.

12 Zerg RA. Hypoperfusion-induced acute renal failure in the rat: an evaluation of oxidant tissue injury. Circ Res 1988;62:430-5

13 Ambrosio G, Flaherty JT, Duilio C, et al. Oxygen radicals generated at reflow induce peroxidation of membrane lipids in reperfused hearts. J Clin Invest 1991;87:2056-66. erman MV, Elliot WC, Gorlin R. An electrocardiographic, anatomic and metabolic study of zonal myocardia ischemia in coronary heart disease. Circulation 1967;35:834-46.

15 Apstein CS, Gravino F, Hood Jr WB. Limitations of lactate production as an index of myocardial ischaemia. Circulation 1979;60:877-88.

16 Serruys PW, Juilliere Y, Zijlstra F, et al. Coronary blood flow velocity during percutaneous transluminal coronary angioplasty as a guide for assessment of the functional angioplasty as a guide for assessme

17 Romaschin AD, Wilson GJ, Thomas U, Feitler DA, Tumiata L, Mickle DAG. Subcellular distribution of peroxidized lipids in myocardial reperfusion injury $-A m J$ peroxidized lipids in myocar

18 Harland WA, Gilbert JD, Steel G, Brooks CJW. Lipids of human atheroma. Part 5: the occurrence of a new group of polar sterol esters in various stages of human atherosclerosis. Atherosclerosis 1971;13:239-46.

19 Ledwozyw A, Michalak J, Stiepien A, Kadziolka A. The relationship between plasma triglycerides, cholesterol, total lipids and lipid peroxidation products during human atherosclerosis. Clin Chim Acta 1986;155:275-84.

20 Hamberg M, Svensson J, Sammuelson B. Prostaglandin endoperoxides. A new concept concerning the mode of action and release of prostaglandins. Proc Natl Acad Sci USA 1974;71:3824-8.

21 Smith JB, Ingerman GM, Silver MJ. Malondialdehyde formation as an indicator of prostaglandin production by human platelets. J Lab Clin Med 1976;88:167-72.

2 Slater TF Free radical mechanisms in tissue injury. Biochem $J$ 1984;222:1-15.

23 Capdevila J, Marnett LJ, Chacos N, Prough RA, Estabrook $\mathrm{RW}$. Cytochrome P-450-dependent oxygenation of arachidonic acid to hydroxyeicosatetraenoic acids. Proc Natl Acad Sci USA 1982;79:767-70.

24 Demopoulos HB, Flamm ES, Pietronigro DD, Seligman ML. The free radical pathology and the microcirculation in the major central nervous system disorders. Acta Physiol Scand Suppl 1980;492:91-119.

25 Gray E. Barrowcliffe TW. Inhibition of antithrombin III by lipid peroxides. Thromb Res 1985;37:241-50.

26 Barrowcliffe TW, Gutteridge JM, Gray E Oxygen radicals, lipid peroxidation and the coagulation system. Agents Actions 1987;22:347-8.

27 Barrowcliffe TW, Gutteridge JMC, Dormandy TL. The effects of fatty acid autoxidation products on blood coagulation. Thrombosis et Diathesis Haemorrhogica 1975;23:271-7.

28 Shiki K, Hearse DJ. Preconditioning of ischaemic myocardium: reperfusion-induced arhythmias. Am J Physiol 1987;253:H1470-6.

29 Charles EM, Vincent JR, Keith AR, Robert BJ. Ischemic preconditioning slows energy metabolism and delays ultrastructural damage during a sustained ischemic episode. Circ Res 1990;66:913-31.

30 Perry RA, Seth A, Hunt A, et al. Balloon occlusion during coronary angioplasty as a model of myocardial ischaemia: reproducibility of sequential inflations. Eur Heart $J$ 1989;10:791-800.

31 Feldman RI, MacDaonald RG, Hill JA, Linacher MC, Conti CR, Pepine CJ. Effect of propranolol on myocardial ischemia occurring during acute coronary occlusion. Circulation 1986;73:727-33.

32 Zalewski A, Goldberg S, Dervan JP, Slysh S, Maroko PR. Myocardial protection during transient coronary artery
occlusion in man: Beneficial effects of regional $\beta$-adrenergic occlusion in man: Beneficial effects of $r$

33 Deutsch E, Berger M, Kussmaul WG, Hirshfield Jr JW, Herrmann HC, Laskey WK. Adaptation to ischemia during percutaneous transluminal coronary angioplasty. Circulation 1990;82:2044-51.

34 Reimer KA, Murry CE, Jennings RB. Cardiac adaptation to ischemia. Circulation 1990;82:2266-8. 
tant long term. Regional pacing practice in the Northern Region has changed in response to the recommendations of the British Pacing and Electrophysiology group. The major change has been where the cost is least-atrial pacing for sinus node dysfunction. Implementation of the full proposals for DDD and rate responsive pacing would considerably increase expenditure on pacing hardware. In a cash limited service the potential benefit of a suggested change in treatment must be weighed against the extra expense and inconvenience.
1 Report of a working party of the British Pacing and Electrophysiology Group. Recommendations for pacemaker prescription for symptomatic bradycardia. $\mathrm{Br}$ Heart J 1991;66:185-91.

2 Rosenqvist M, Brandt J, Schuller $\mathrm{H}$. Long term pacing in sinus node disease; effects of stimulation mode on cardiovascular morbidity and mortality. Am Heart J 1988; 116:16-22.

3 Bianconi L, Boccadamo R, Di Florio A, et al. Atrial versus ventricular stimulation in sick sinus syndrome; effects on morbidity and mortality [abstract]. PACE 1989;12:1236

4 Perrins JE, Morley CA, Chan SL, Sutton R. Randomised controlled trial of physiological and ventricular pacing. $\mathrm{Br}$ Heart J 1983;50:112-7.

5 Sutton $\mathrm{R}$, Ingram A, Briers $\mathrm{L}$, et al. Ten years of physiological cardiac pacing. In: Belhassen B, Feldman S, Copperman Y, eds. Cardiac pacing and electrophysiology. Jerusalem: R\&L Creative Communications, 1987:141-2.

\section{Correction}

Coronary venous lipid peroxide concentrations after coronary angioplasty: correlation with biochemical and electrocardiographic evidence of myocardial ischaemia. $K G$ Oldroyd, $J R$ Paterson, A G Rumley, H Eteiba, A P Rae, J Shepherd, $S M$ Cobbe, I Hutton (July issue, volume 68: pages 43-7.) There were several editorial mistakes in figure 3 of this paper, for which we apologise. A correct version is shown on the right.
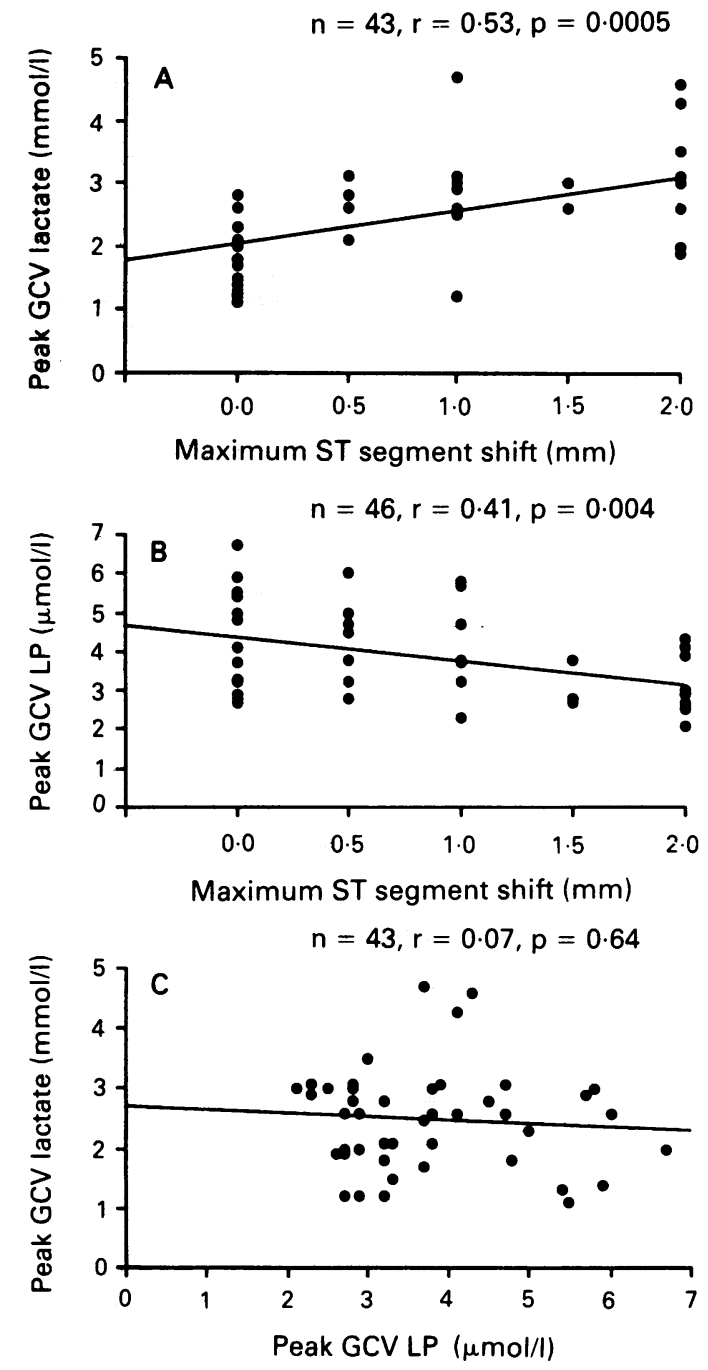

Figure 3 Simple linear regression analysis of the relation between $(A)$ peak lactate concentration in the great cardiac vein (GCV) and maximum $S T$ segment shift; (B) peak GCV lipid peroxide (LP) concentration and maximum $S T$ segment shift; (C) peak GCV lactate concentration and LP concentration. 